\title{
The Impact of Supply Chain Cooperative Relationship on Performance: A Knowledge Management Perspective
}

\author{
Andong Tian \\ School of Business Administration, South China University of Technology, Guangzhou, China \\ Email: 2411797462@qq.com
}

How to cite this paper: Tian, A.D. (2018) The Impact of Supply Chain Cooperative Relationship on Performance: A Knowledge Management Perspective. Journal of Service Science and Management, 11, 44-55.

https://doi.org/10.4236/jssm.2018.111005

Received: December 12, 2017

Accepted: February 6, 2018

Published: February 9, 2018

Copyright $\odot 2018$ by author and Scientific Research Publishing Inc. This work is licensed under the Creative Commons Attribution International License (CC BY 4.0).

http://creativecommons.org/licenses/by/4.0/

\begin{abstract}
There have been several studies focusing on the impact of supply chain cooperative relationship on performance, which is mainly based on transaction cost theory and the resource-based view theory. Our study deeply analyzes the inner mechanism between supply chain cooperative relationship and its performance from a perspective of knowledge management. We totally collected 136 valid samples in the questionnaire survey. Through the empirical study, we find: 1) Supply chain cooperative relationship has an obviously positive impact on performance; 2) Knowledge sharing is a partial mediator variable between supply chain cooperative relationship and performance; 3) Environmental uncertainty takes a positive regulating effect for supply chain cooperative relationship to promote knowledge sharing between enterprises, but has no obvious effect for the influence of knowledge sharing to performance. According to findings above, our study is aimed to provide some suggestions to Chinese enterprises on a knowledge management perspective.
\end{abstract}

\section{Keywords}

Supply Chain Performance, Supply Chain Cooperative Relationship, Knowledge Sharing, Environmental Uncertainty

\section{Introduction}

The tendency of global economy and Internet technology make a huge impact on development of industries involving supply chain. By reason that supply chain is composed of the relative upstream and downstream companies, the managers need not only to focus on a single company but also to consider cooperative relationship between them, to promote supply chain performance totally. 
Supply Chain Cooperative Relationship means aligning the activities of two or more organizations in the supply chain to coordinate the supply of goods or services, creating a competitive advantage through improved service or efficiency improvements [1]. And Supply Chain Performance refers to the extended supply chain's activities in meeting end-customer requirements, including product availability, on-time delivery, and all the necessary inventory and capacity in the supply chain to deliver that performance in a responsive manner [2]. According to relative literature reviews, we find previous studies show supply chain cooperative relationship is positively related to its performance. There are some based theories as follows: According to transaction cost theory, when company partnership is under the contract of both sides, transaction cost will decrease and transaction success rate will increase. According to resource-based view theory, different companies have resources with high heterogeneity. For acquiring and sharing outer resources, companies need to maintain a long-term partnership [3]. In previous empirical studies, some researchers explore the influence of supply chain cooperative relationship features on performance [4], and others focus on the indirect effect of above process. They find supply chain collaboration [5], supply chain integration [6] and information sharing [7] can be an indirect variable.

However, researchers seldom think about effect of knowledge in above process [8]. With the coming of knowledge economy, knowledge has become the most important strategic resource for a company. So researchers should focus more on how the knowledge can spread and share among different companies, and what effect it will make on these companies. As for supply chain, knowledge flows and shares both in and out of companies, so we choose knowledge to explore the intermediate mechanism of supply chain cooperative relationship and performance. Also, because the high-tech industry is more likely to be affected by knowledge, so we choose high-tech industry and narrow our study scope to it.

\section{Model}

In performance-relative studies, "input-process-output" structure is widely used to construct performance model, which is so-called IPO model [9]. As for supply chain performance, most studies are about "input" part, namely the independent variable, and few studies are about "process" part. Under the background of knowledge economy, what is the effect of knowledge in "process" part? We infer that: in a close relationship, supply chain companies are more likely to believe in their cooperators, and are willing to share their knowledge, which leads to form a constant increment knowledge value chain. Then the knowledge value chain will transform to core competence of companies [10] and finally promote whole supply chain performance. Therefore, we choose knowledge sharing as a mediator variable and environment uncertainty as a moderator variable in our study model.

We refer to Fynes' study (2005) to divide our variable supply chain cooperative relationship to 4 dimensions: trust, commitment, communication and 
adaptation. Knowledge can be divided to explicit knowledge and implicit knowledge by judging whether it can be encoded with formal and systematic language and record clearly. Different kinds of knowledge make different influences on knowledge sharing, so we will divide knowledge to explicit knowledge and implicit knowledge. Researcher Beamon proposes that supply chain performance can be divided to resource, output, and flexibility three sides, in which resource side includes cost, inventory, and return on investment (ROI), with the goal of minimum cost and maximum efficiency; output side mainly include market, aiming at high quality of production service and customer satisfaction; flexibility side focuses on a company's ability to make immediate response when facing uncertainty. We choose Beamon's method to divide supply chain performance after considering both our study object and uncertain factors.

\section{Hypothesis}

\subsection{Supply Chain Cooperative Relationship and Performance}

In supply chain, for achieving the presupposed goal, companies will build the cooperative relationship with each other [11]. In our study, we will start up with trust, commitment, communication and adaptation.

1) Trust and Performance

Trust means a company has the confidence with its partners' integrity and reliability. High trust level is helpful to decrease exchange cost between companies, and increase success probability of transaction [12], which promotes performance of resource side; good trust relationship will motivate company resource sharing and innovation ability, which helps to provide better production service, and promotes performance of output side; Moreover, trust can also maintain a long-term partnership and reduce uncertainty [8].

2) Commitment and Performance

Commitment means a company makes a promise to its partner for performing duties and obligations. In supply chain, commitment make companies respect with each other [13], and maintain a long-term relationship; A steady relationship makes it possible for a company to obtain others' scare resource and market competitive advantage [14], which ensures a stronger flexible performance.

3) Communication and Performance

Communication means an information exchange method of companies' for promoting cooperation and performance. Firstly, previous studies show that communication can not only increase trust of both sides [15], but also make a positive effect on commitment [16]; Secondly, communication between companies can allocate inner resources immediately to face with a rapidly changing environment, and promote flexible performance [17].

4) Adaption and Performance

Adaption means the integration degree of companies' cooperative process. The better the adaption is, the more possible for companies to adapt with each 
other, and the easier to solve conflicts [18], which roundly promotes performance of resource, output and flexibility sides. We propose the hypothesis as follows:

H1: Supply chain cooperative relationship has positive effect on performance;

H1a: Supply chain cooperative relationship has positive effect on resource performance;

H1b: Supply chain cooperative relationship has positive effect on output performance;

H1c: Supply chain cooperative relationship has positive effect on flexible performance.

\subsection{Supply Chain Cooperative Relationship and Knowledge Sharing}

Besides the lack of constraining and driving force, knowledge sharing in supply chain faces more difficulties than that in internal company. In a trust-based partnership, both sides of company have faith in their cooperation or transaction, and they think it unnecessary to prevent themselves from opportunistic practice of others, so that they are more likely to sharing knowledge with others [19]. There are also some studies infer that commitment is the precondition of knowledge transaction in supply chain [20]. When commitment increases, companies are more likely to maintain their stable long-term partnership, so that they would complement each other's advantages by sharing more knowledge, rather than do something harmful to others' benefit [8]. Moreover, for cooperative relationship, it may have some different impact on explicit knowledge and implicit knowledge. Because of the highly abstract essence, implicit knowledge relies more on close partnership [21], compared with explicit knowledge. Some study results show high level trust between companies will make a stronger influence on implicit knowledge transfer than that on explicit knowledge [22]. We propose the hypothesis as follows:

H2: Supply chain cooperative relationship has positive effect on knowledge sharing;

H2a: Supply chain cooperative relationship has positive effect on explicit knowledge sharing;

H2b: Supply chain cooperative relationship has positive stronger effect on implicit knowledge sharing than that on explicit knowledge.

\subsection{Knowledge Sharing and Supply Chain Performance}

The effect paths from knowledge sharing to supply chain performance mainly include as follows: First, knowledge sharing helps companies to obtain both inner and outer resources, and companies could integrate them to self development strategy [23], to promote resource performance; Second, knowledge communication and interaction increase group knowledge storage, which lays the foundation of innovation and creation [9], improves the quality of product and 
service, and leads to output performance promotion; Third, knowledge will gain value when flowing in every section of sharing process, which strengthens study ability and core competence of companies [10], so that companies could make faster reaction when facing changing environment, and their flexible performance will be promoted. We propose the hypothesis as follows:

H3: Knowledge sharing has positive effect on supply chain performance;

H3a: Explicit knowledge sharing has positive effect on resource performance;

H3b: Explicit knowledge sharing has positive effect on out-performance;

H3c: Explicit knowledge sharing has positive effect on flexible performance;

H3d: Implicit knowledge sharing has positive effect on resource performance;

H3e: Implicit knowledge sharing has positive effect on out-performance;

H3f: Implicit knowledge sharing has positive effect on flexible performance.

\subsection{Mediating Effect of Knowledge Sharing}

Previous study about supply chain performance shows that, many independent variables are not directly related to performance, there also exist some mediator variables [9]. For example, Zhang choose knowledge transaction as a mediator variable in the process between supply chain cooperative relationship and performance [8]. Ye also finds supply chain cooperative relationship has an indirect effect on performance through information sharing. Base on good partnership, knowledge could transmit among supply chain member companies smoothly and integrate freely, and cause positive effect on the whole performance of supply chain. Because implicit knowledge relies more on cooperative relationship [22], and is more crucial to promote performance [24], so we infer implicit knowledge has stronger mediating effect that explicit knowledge. We propose the hypothesis as follows:

H4: Knowledge sharing has mediating effect in process from supply chain cooperative relationship to performance;

H4a: Explicit knowledge sharing has mediating effect in process from supply chain cooperative relationship to performance;

H4b: Implicit knowledge sharing has mediating effect in process from supply chain cooperative relationship to performance.

\subsection{Moderating Effect of Environment Uncertainty}

1) Moderating Effect of Environment Uncertainty between Supply Chain Cooperative Relationship and Knowledge Sharing

Relative study shows, company cooperation is helpful to decrease negative effect of environment uncertainty [25]. Therefore, when in a highly uncertain environment, companies tend to reinforce cooperative relationship, to avoid benefit harm of uncertainty and gain more survival advantage. Oppositely, when level of environment uncertainty is low, companies don't have a strong cooperation motivation, and it can't promote the effect of cooperative relationship on performance. We propose the hypothesis as follows: 
H5: Environment uncertainty has positive moderating effect between supply chain cooperative relationship and knowledge sharing;

2) Moderating Effect of Environment Uncertainty between Knowledge Sharing and Supply Chain Performance

Uncertainty will cause knowledge transaction barrage [8] and make negative influence on knowledge sharing [26] in supply chain cooperation process. Because of negative effect of uncertainty, when faced with more risks and challenges, companies will be more cautious to have less willing to cooperate with others, which makes knowledge sharing more difficult [27], and leads to low performance. Oppositely, when level of environment uncertainty is low, companies will spurn previous conservative strategy, and make use of knowledge sharing to realize performance growth. We propose the hypothesis as follows:

H6: Environment uncertainty has negative moderating effect between knowledge sharing and supply chain performance.

In conclusion of Section 2 and Section 3 above, we build our study model (Figure 1) as follows.

\section{Method and Data Analysis}

\subsection{Questionnaire}

Our study choose questionnaire to collect data. The questionnaire includes following 5 sections: basic information, supply chain cooperation relationship scale, knowledge sharing scale, supply chain performance scale and environment uncertainty scale, with seven point Likert scale method. And every scale all refer to maturity scales of relative fields.

We randomly sample some target companies within the field of high-tech industry in the area of Yangtze River Delta Region, Pearl River Delta Region and Wuhan Region. We totally give out 155 questionnaires, collect 140 questionnaires, which means a recovery rate of $90.3 \%$. After discarding 4 invalid items, we finally collect 136 valid questionnaires, which means a valid recovery rate of 87.7\%. Among the participants above, most enterprises are in relative industries of semiconductor, electronics, photovoltaic and computer science, with an establishment age from 10 to 30 years, and a stuff scale from 500 to 1000 people. About the $80.1 \%$ of that are males, and rest of $19.9 \%$ are females, in which

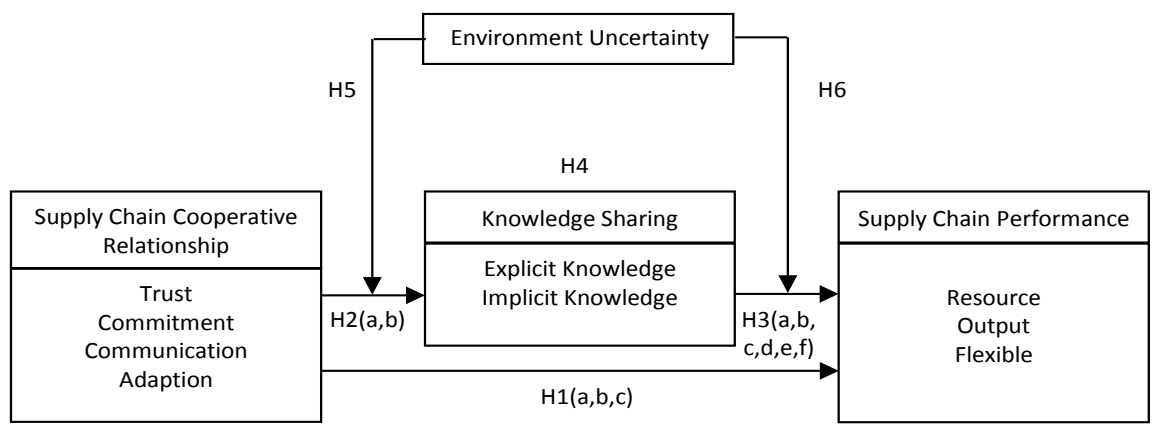

Figure 1. Study model. 
almost of them are middle or senior managers, with 3 to 15 years of working experience.

We choose Cronbach's a to measure reliability of questionnaire. The result shows, the value of trust, commitment, communication and adaption respectively are $0.606,0.734,0.745$ and 0.788 ; the value of explicit knowledge sharing and implicit knowledge sharing respectively are 0.710 and 0.652 ; the value of resource, output and flexible performance respectively are $0.806,0.903$ and 0.851 ; the value of environment uncertainty is 0.912 . In conclusion, our questionnaire is reliable. After KMO and Bartlett's Test of Sphericity, we continue an exploratory analysis, and finally get the result: the factor loading of every variable are above 0.5 , and their cumulative interpretation of variance are above $64 \%$, which means our questionnaire has a good structure validity.

\subsection{Hypothesis Verification}

\section{1) Correlation Analysis}

We choose SPSS to make statistics and analysis of the collected questionnaires. The result of correlation analysis shows, the correlation coefficient of implicit knowledge sharing and resource performance is not significant, which is contrary to $\mathrm{H} 3 \mathrm{~d}$, and other results preliminarily support $\mathrm{H} 1(\mathrm{a}, \mathrm{b}, \mathrm{c}), \mathrm{H} 2(\mathrm{a}, \mathrm{b})$, H3(a, b, c, e, f). All results are shown in Table 1, and the data is from SPSS result of our study.

2) Regression Analysis

We choose regression analysis to verify the causality of each variable, and verify our hypothesis.

Table 1. Correlation of each variable $(\mathrm{N}=136)$.

\begin{tabular}{cccccccccc}
\hline & SCCR & EKS & IKS & KS & EU & RP & OP & FP & SCP \\
\hline SCCR & 1 & & & & & & & \\
ESK & $0.294^{* * *}$ & 1 & & & & & & \\
IKS & $0.606^{* * *}$ & $0.629^{* * *}$ & 1 & & & & & \\
KS & $0.482^{* * *}$ & $0.856^{* * *}$ & $0.821^{* * *}$ & 1 & & & & \\
EU & $0.708^{* *}$ & $0.766^{* *}$ & $0.799^{* * *}$ & $0.830^{* * *}$ & 1 & & & \\
RP & $0.252^{* *}$ & $0.391^{* * *}$ & 0.091 & $0.264^{* *}$ & $0.717^{* * *}$ & 1 & & & \\
OP & $0.701^{* * *}$ & $0.523^{* * *}$ & $0.685^{* * *}$ & $0.649^{* * *}$ & $0.610^{* * *}$ & $0.881^{* * *}$ & 1 & & \\
FP & $0.678^{* * *}$ & $0.512^{* * *}$ & $0.790^{* * *}$ & $0.700^{* * *}$ & $0.601^{* * *}$ & $0.633^{* * *}$ & $0.698^{* * *}$ & 1 & \\
SCP & $0.786^{* * *}$ & $0.695^{* * *}$ & $0.611^{* * *}$ & $0.559^{* * *}$ & $0.677^{* * *}$ & $0.755^{* * *}$ & $0.609^{* * *}$ & $0.699^{* * *}$ & 1 \\
Mean & 4.892 & 4.977 & 4.86 & 4.919 & 5.019 & 4.953 & 5.013 & 4.614 & 4.86 \\
Std. & 0.8074 & 1.0626 & 1.0398 & 1.0435 & 0.8557 & 1.1432 & 1.1449 & 0.9956 & 1.1045 \\
\hline
\end{tabular}


The regression results of supply chain cooperation relationship and performance are shown in Table 2 below, and the data is from SPSS result of our study. We can draw a conclusion that H1, H1a, H1b, H1c are all supported.

The regression results of supply chain cooperation relationship and knowledge sharing are shown in Table 3 below, and the data is from SPSS result of our study. We can draw a conclusion that $\mathrm{H} 2, \mathrm{H} 2 \mathrm{a}, \mathrm{H} 2 \mathrm{~b}$ are all supported.

The regression results of knowledge sharing and performance are shown in Table 4 below, and the data is from SPSS result of our study. We can draw a conclusion that $\mathrm{H} 3, \mathrm{H} 3 \mathrm{a}, \mathrm{H} 3 \mathrm{~b}, \mathrm{H} 3 \mathrm{c}, \mathrm{H} 3 \mathrm{e}, \mathrm{H} 3 \mathrm{f}$ are supported, except that $\mathrm{H} 3 \mathrm{~d}$ are not supported $(\mathrm{P}=0.294>0.5)$.

To verify mediating effect, we refer Wen's method to avoid type I or II statistical error rates [28]. The result is shown in Table 5, and the data is from SPSS result of our study.

According to the discriminant coefficients above, knowledge sharing $(\mathrm{a}=$ $\left.0.394^{\star * *}\right)$ and implicit knowledge sharing $\left(\mathrm{a}=0.606^{\star * *}\right)$ has a partial mediating effect, $\mathrm{H} 4$ and H4b are supported. But explicit knowledge sharing $(\mathrm{a}=0.134)$ is not significant, we need continue a Sobel verification, shown in Table 6, and the data is from SPSS result of our study.

The result shows statistics $\mathrm{Z}$ is 5.934 , whose absolute value is larger than critical value (0.97), which means $\mathrm{p}$ is less than 0.05 , so explicit knowledge sharing also has a partial mediating effect, $\mathrm{H} 4 \mathrm{~b}$ is supported.

Table 2. Regression analysis of SCCR and SCP $(\mathrm{N}=136)$.

\begin{tabular}{|c|c|c|c|c|c|c|c|c|}
\hline & \multicolumn{2}{|r|}{ SCP } & \multicolumn{2}{|c|}{$\mathrm{RP}$} & \multicolumn{2}{|r|}{$\mathrm{OP}$} & \multicolumn{2}{|r|}{ FP } \\
\hline & $\beta$ & $\mathrm{T}$ & $\beta$ & $\mathrm{T}$ & $\beta$ & $\mathrm{T}$ & $\beta$ & $\mathrm{t}$ \\
\hline $\operatorname{SCCR~H1,~H1(a,b,~c)~}$ & 0.786 & $14.697^{\star \star *}$ & 0.252 & $3.02^{\star *}$ & 0.701 & $11.39^{\star * *}$ & 0.678 & $10.69^{* * *}$ \\
\hline F-Statistics & \multicolumn{2}{|c|}{$215.991^{\star * *}$} & \multicolumn{2}{|c|}{$9.112^{\star *}$} & \multicolumn{2}{|c|}{$129.695^{\star * *}$} & \multicolumn{2}{|c|}{$114.202^{\star * *}$} \\
\hline $\mathrm{R}^{2}$ & \multicolumn{2}{|r|}{0.617} & \multicolumn{2}{|c|}{0.064} & \multicolumn{2}{|c|}{0.492} & \multicolumn{2}{|c|}{0.46} \\
\hline Adjusted R2 & \multicolumn{2}{|c|}{0.614} & \multicolumn{2}{|c|}{0.057} & \multicolumn{2}{|c|}{0.488} & \multicolumn{2}{|c|}{0.456} \\
\hline Constant B & \multicolumn{2}{|r|}{2.151} & \multicolumn{2}{|c|}{0.247} & \multicolumn{2}{|c|}{0.783} & \multicolumn{2}{|c|}{0.835} \\
\hline Sig. & \multicolumn{2}{|r|}{0} & \multicolumn{2}{|c|}{0.003} & \multicolumn{2}{|r|}{0} & \multicolumn{2}{|r|}{0} \\
\hline
\end{tabular}

Table 3. Regression analysis of SCCR and KS $(\mathrm{N}=136)$.

\begin{tabular}{ccccccc}
\hline & \multicolumn{2}{c}{ KS } & \multicolumn{2}{c}{ EKS } & \multicolumn{2}{c}{ IKS } \\
\hline & $\beta$ & $\mathrm{T}$ & $\beta$ & $\mathrm{T}$ & $\beta$ & $\mathrm{t}$ \\
\hline SCCR H2, H2 (a, b) & 0.482 & $8.77^{* * *}$ & 0.294 & $3.411^{* * *}$ & 0.606 & $8.824^{* * *}$ \\
F-Statistics & $45.311^{* * *}$ & \multicolumn{1}{c}{$11.967^{\star * *}$} & $77.857^{* * *}$ \\
$\mathrm{R}^{2}$ & 0.232 & 0.086 & 0.367 \\
Adjusted R2 & 0.229 & 0.081 & 0.363 \\
Constant B & 0.237 & 0.261 & 0.543 \\
Sig. & 0 & 0 & 0 \\
\hline
\end{tabular}


Table 4. Regression analysis of KS and SCP $(\mathrm{N}=136)$.

\begin{tabular}{|c|c|c|c|c|c|c|c|c|}
\hline & \multicolumn{2}{|c|}{ SCP } & \multicolumn{2}{|c|}{$\mathrm{RP}$} & \multicolumn{2}{|r|}{ OP } & \multicolumn{2}{|r|}{ FP } \\
\hline & $\beta$ & $\mathrm{T}$ & $\beta$ & $\mathrm{T}$ & $\beta$ & $\mathrm{T}$ & $\beta$ & $\mathrm{t}$ \\
\hline KS H3 & 0.559 & $7.80^{* * *}$ & 0.264 & $3.17^{\star *}$ & 0.649 & $9.87^{\star * *}$ & 0.7 & $11.34^{* * *}$ \\
\hline F-Statistics & \multicolumn{2}{|c|}{$60.907^{\star *}$} & \multicolumn{2}{|c|}{$10.072^{\star \star}$} & \multicolumn{2}{|c|}{$97.600^{\star * *}$} & \multicolumn{2}{|c|}{$128.597^{\star * *}$} \\
\hline $\mathrm{R}^{2}$ & \multicolumn{2}{|c|}{0.312} & \multicolumn{2}{|c|}{0.07} & \multicolumn{2}{|c|}{0.421} & \multicolumn{2}{|c|}{0.49} \\
\hline Adjusted R2 & \multicolumn{2}{|c|}{0.307} & \multicolumn{2}{|c|}{0.063} & \multicolumn{2}{|c|}{0.417} & \multicolumn{2}{|c|}{0.486} \\
\hline Constant B & \multicolumn{2}{|c|}{0.521} & \multicolumn{2}{|c|}{0.205} & \multicolumn{2}{|c|}{0.854} & \multicolumn{2}{|c|}{1.015} \\
\hline \multirow[t]{2}{*}{ Sig. } & \multicolumn{2}{|c|}{0} & \multicolumn{2}{|c|}{0} & \multicolumn{2}{|r|}{0} & \multicolumn{2}{|r|}{0} \\
\hline & $\beta$ & $\mathrm{T}$ & $\beta$ & $\mathrm{T}$ & $\beta$ & $\mathrm{T}$ & $\beta$ & $\mathrm{t}$ \\
\hline EKS H3(a, b, c) & & & 0.391 & $4.91^{* * *}$ & 0.523 & $7.11^{\star * *}$ & 0.512 & $6.95^{\star * \star}$ \\
\hline F-Statistics & & & \multicolumn{2}{|c|}{$24.237^{\star * *}$} & \multicolumn{2}{|c|}{$50.571^{\star * *}$} & \multicolumn{2}{|c|}{$47.0685^{\star * *}$} \\
\hline $\mathrm{R}^{2}$ & & & \multicolumn{2}{|c|}{0.153} & \multicolumn{2}{|c|}{0.274} & \multicolumn{2}{|c|}{0.262} \\
\hline Adjusted R2 & & & \multicolumn{2}{|c|}{0.147} & \multicolumn{2}{|c|}{0.269} & \multicolumn{2}{|c|}{0.257} \\
\hline Constant B & & & & & & .622 & & .671 \\
\hline Sig. & & & & & & 0 & & 0 \\
\hline & $\beta$ & $\mathrm{T}$ & $\beta$ & $\mathrm{T}$ & $\beta$ & $\mathrm{T}$ & $\beta$ & $\mathrm{t}$ \\
\hline IKS H3(d, e, f) & & & 0.091 & -1.05 & 0.682 & $10.799^{* * *}$ & 0.79 & $14.91^{\star * *}$ \\
\hline F-Statistics & & & 1.1 & $2^{* * *}$ & & $623^{* * *}$ & & $.365^{* * *}$ \\
\hline $\mathrm{R}^{2}$ & & & & & & .465 & & .624 \\
\hline Adjusted R2 & & & & & & .461 & & .621 \\
\hline Constant B & & & & 999 & & .851 & & .087 \\
\hline Sig. & & & & 94 & & 0 & & 0 \\
\hline
\end{tabular}

Table 5. Mediating effect verification of KS $(\mathrm{N}=136)$.

\begin{tabular}{cccccc}
\hline Discriminant coefficient & & KS & EKS & IKS & SCP \\
\hline c & SCCR & & & & $0.786^{* * *}$ \\
a & SCCR & $0.394^{* * *}$ & 0.134 & $0.606^{* * *}$ & \\
c' & SCCR & $0.669^{* * *}$ & $0.752^{* * *}$ & $0.578^{* * *}$ & \\
b & KS & $0.295^{* * *}$ & & & \\
b1 & EKS & & $0.249^{* * *}$ & & \\
b2 & IKS & & & $0.343^{* * *}$ & \\
\hline
\end{tabular}

Table 6. Sobel verification of EKS $(\mathrm{N}=136)$.

\begin{tabular}{ccccccc}
\hline Causality & Mediator & $A$ & $S_{a}$ & $B$ & $S_{b}$ & $Z$ \\
\hline SCCR-SCP & EKS & 0.134 & 0.080 & 0.249 & 0.039 & 5.934 \\
\hline
\end{tabular}


According to Table 7, which is from SPSS result of our study, we can draw a conclusion that $\mathrm{H} 5$ is supported $\left(\Delta \mathrm{R}^{2}=0.065\right)$, but $\mathrm{H} 6$ is not supported $\left(\Delta \mathrm{R}^{2}=\right.$ $0.001, \beta$ of $\mathrm{KS}^{*} \mathrm{EU}$ is not significant).

\section{Conclusions}

After above theoretical derivation and empirical analysis, we can draw the conclusion that: 1) Supply chain cooperative relationship has an obviously positive impact on performance; 2) Knowledge sharing is a partial mediator variable between supply chain cooperative relationship and performance, and implicit knowledge sharing has stronger mediating effect than explicit knowledge sharing; 3) Environmental uncertainty takes a positive regulating effect for supply chain cooperative relationship to promote knowledge sharing between enterprises, but has no obvious effect for the influence of knowledge sharing to performance. These study results not only provide relative theory basis for supply chain management research, but also provide guidance to managers to take measures to enhance company partnership, promote knowledge sharing, and supply chain performance: 1) Establish a common value, to decrease cooperation resistance and knowledge differences between partners; 2) Establish relative motivation and restriction system, and reify the benefit included; 3) Use modernized method, such as mobile office app and remote meeting system, to improve intercompany knowledge sharing level; 4) Attach importance to the effect of implicit knowledge to company performance, build the intercompany communication and share mechanism.

The restriction of our study is, first, we only focus on the mediating effect of knowledge sharing, but there are many other sections in the whole knowledge

Table 7. Moderating effect of EU $(\mathrm{N}=136)$.

\begin{tabular}{|c|c|c|c|c|c|c|c|c|}
\hline \multirow[b]{3}{*}{ Variable } & \multicolumn{2}{|l|}{ M1 } & \multicolumn{2}{|l|}{ M2 } & \multicolumn{2}{|l|}{ M3 } & \multicolumn{2}{|l|}{ M4 } \\
\hline & \multicolumn{2}{|l|}{ KS } & \multicolumn{2}{|l|}{ KS } & \multicolumn{2}{|l|}{ SCP } & \multicolumn{2}{|l|}{ SCP } \\
\hline & $\beta$ & $\mathrm{T}$ & $\beta$ & $\mathrm{T}$ & $\beta$ & $\mathrm{T}$ & $\beta$ & $\mathrm{T}$ \\
\hline SCCR & $0.171^{\star *}$ & 1.953 & $0.191^{\star *}$ & 2.211 & & & & \\
\hline $\mathrm{EU}$ & $0.409^{* * *}$ & 6.831 & $0.390^{\star * *}$ & 6.829 & & & & \\
\hline $\mathrm{SCCR}^{\star} \mathrm{EU}$ & & & $0.448^{\star * *}$ & 3.934 & & & & \\
\hline KS & & & & & $0.296^{\star * *}$ & 3.831 & $0.296^{* * *}$ & 9.246 \\
\hline $\mathrm{EU}$ & & & & & $0.284^{\star * *}$ & 4.827 & $0.283^{* * *}$ & 4.783 \\
\hline $\mathrm{KS}^{*} \mathrm{EU}$ & & & & & & & 0.067 & 0.577 \\
\hline $\mathrm{R}^{2}$ & 0.375 & & 0.44 & & 0.415 & & 0.416 & \\
\hline Adj. $R^{2}$ & 0.365 & & 0.427 & & 0.406 & & 0.403 & \\
\hline F & 39.824 & & 34.597 & & 47.171 & & 31.4 & \\
\hline$\Delta \mathrm{R}^{2}$ & & & 0.065 & & & & 0.001 & \\
\hline
\end{tabular}


management, so we can do further study on the mediating effect of these different sections; second, our study only cover the supply chain of several industries, we can explore more fields, such as some restructuring traditional industries or the industries with combination of high-tech and tradition.

\section{References}

[1] Cox, S.A. and Perkins, J.S. (2008) Factors for Effective E-Collaboration in the Supply Chain. Encyclopedia of E-Collaboration, 1-7.

https://doi.org/10.4018/978-1-59904-000-4.ch043

[2] Hausman, W.H. (2004) Supply Chain Performance Metrics. In: The Practice of Supply Chain Management. Where Theory and Application Converge. International Series in Operations Research \& Management Science, Vol. 62, Springer, Boston, MA, 61-73.

[3] Peteraf, M.A. (1993) The Cornerstones of Competitive Advantage: A Resource-Based View. Strategic Management Journal, 14, 179-191.

https://doi.org/10.1002/smj.4250140303

[4] Jiang, C.C. (2012) Research on Supply Chain Partnership and Supply Chain Performance-Taking Partnership Characteristics as a Moderator. Science and Technology Management Research, 32, 236-241.

[5] Zen, W.J. and Ma, S.H. (2010) The Impact of Supply Chain Relationship on Collaboration and Supply Chain Performance in Manufacturing Industry. Chinese Journal of Management, 7, 1221-1227.

[6] Pan, W.N. (2006) A Empirical Research on Supply Chain Partnership, Integration Ability and Cooperation Performance. Science \& Technology Progress and Policy, 23, 105-108.

[7] Deng, M.R. and Jiang, X.L. (2013) The Effect of Partnership and Information Sharing on Supply Chain Performance in Manufacturing Outsourcing. Commercial Research, 7, 28-32.

[8] Zhang, X.M. and Chen, W. (2011) Trust, Relationship Commitment and Cooperative Performance in Supply Chain-An Empirical Study Based on Perspective of Knowledge Trading. Studies in Science of Science, 12, 1865-1874.

[9] Jin, L.L. and Li, D.H. (2012) Research on the Effect of Scientific Research Team Members' Interdisciplinary Characteristics on Innovation Performance-The Mediating Roles of Knowledge Sharing and Integration. Studies in Science of Science, 1, 111-123.

[10] Qin, L.L., Wang, D.P. and Zhou, C. (2011) A Research on Knowledge Supply Chain Core Competence Promotion on Perspective of Knowledge Management. Information studies. Theory \& Application, 34, 72-75.

[11] Rigby, D.K. and Buchanan, W.T. (1994) Putting More Strategy into Strategic Alliances. Directors and Boards, 18, 14-19.

[12] Hagel, J. and Singer, M. (1999) Unbundling the Corporation. Harvard Business Review, 77, 133-141.

[13] Yang, J., Wang, J. and Wong, C.W.Y. (2008) Relational Stability and Alliance Performance in Supply Chain. Omega, 36, 600-608.

[14] Ramaseshan, B., Yip, L.S.C. and Pae, J.H. (2006) Power, Satisfaction, and Relationship Commitment in Chinese Store Tenant Relationship and Their Impact on Performance. Journal of Retailing, 82, 63-70. 
[15] Marshall, D. and Fynes, B. (2004) Environmental Uncertainty, Supply Chain Relationship Quality and Performance. Journal of Purchasing and Supply Management, 10, 179-190. https://doi.org/10.1016/j.pursup.2004.11.003

[16] Gao, W. and Liu, Y. (2010) Collaborative Communication and Enterprise Performance: A Mediating Effect of Commitment and a Moderating Effect of Governance Mechanism. Management World, 11, 76-93.

[17] Gaur, A., Mukherjee, D. and Schmid, F. (2011) Environmental and Firm Level Influences on Inter-Organizational KSust and SME Performance. Journal of Management Studies, 8, 13-25.

[18] Langfiel, S.K. and Reenwood, M.R. (1998) Developing Cooperative Buyer-Supplier Relationships: A Case Study of Toyota. Journal of Management Study, 35, 223-240.

[19] Inkpen, A.C. and Ross, J. (2001) Why Do Some Strategic Alliances Persist beyond Their Useful Life? California Management Review, 44, 132-148.

[20] Morgan, R.M. and Hunt, S.D. (1994) The Commitment-Trust Theory of Relationship Marketing. Journal of Marketing, 58, 20-38.

[21] Polanyi (1966) The Tacit Dimension. The University of Chicago Press, Chicago, $1-128$.

[22] Dhanaraj, C., Lyles, M.A. and Steensma, H.K. (2004) Managing Tacit and Explicit Knowledge KSansfer in IJVs: The Role of Relational Embeddedness and the Impact on Performance. Journal of International Business Studies, 35, 428-442. https://doi.org/10.1057/palgrave.jibs.8400098

[23] Hitt, M.A., Ireland, R.D. and Lee, H. (2000) Technological Learning, Knowledge Management, Firm Growth and Performance. Journal of Engineering and Technology Management, 17, 231-246.

[24] Nonaka, I. and Takeuchi, H. (1995) The Knowledge Creating Company. Oxford University Press, New York.

[25] Williamson, O.E. (1985) The Economic Institutions of Capitalism. Free Press, New York.

[26] Chen, T., Wang, T. and Zhu, Z. (2013) The Distance of Knowledge, Environment Turbulence and the Relationship of Knowledge Sharing in Organization: An Empirical Research Which Contains Moderating Effect. Studies in Science of Science, 31, 1532-1540.

[27] Squire, B., Cousins, P.D. and Brown, S. (2009) Cooperation and Knowledge Transfer within Buyer-Supplier Relationships: The Moderating Properties of KSust, Relationship Duration and Supplier Performance. British Journal of Management, 20, 461-477. https://doi.org/10.1111/j.1467-8551.2008.00595.x

[28] Wen, Z., Zhang, L., Hou, J. and Liu, H. (2004) Testing and Application of the Mediating Effects. Acta Psychologica Sinica, 36, 614-620. 